Dominik Krüger, Patrick Oßwald, Markus Köhler, Patrick Hemberger, Thomas Bierkandt, Yasin Karakaya, Tina Kasper

Hydrogen abstraction ratios: A systematic iPEPICO spectroscopic investigation in laminar flames

Combustion and Flame, Volume 191 (2018) 343-352

The original publication is available at www.elsevier.com

https://doi.org/10.1016/j.combustflame.2017.12.025

(C) 2018. This manuscript version is made available under the CC-BY-NC-ND 4.0 license http://creativecommons.org/licenses/by-nc-nd/4.0/ 


\title{
Hydrogen abstraction ratios: A systematic iPEPICO spectroscopic investigation in laminar flames
}

\author{
Dominik Krüger $^{\mathrm{a}^{*}}$, Patrick Oßwald ${ }^{\mathrm{a}}$, Markus Köhler ${ }^{\mathrm{a}}$, Patrick Hemberger ${ }^{\mathrm{b}}$, Thomas Bierkandt ${ }^{\mathrm{c}, \mathrm{a}}$, Yasin \\ Karakaya $^{\mathrm{c}}$ and Tina Kasper ${ }^{\mathrm{c}}$ \\ ${ }^{a}$ German Aerospace Center (DLR) - Institute of Combustion Technology, Stuttgart 70569, Germany \\ ${ }^{b}$ Laboratory for Femtochemistry and Synchrotron Radiation, Paul Scherrer Institute, CH-5232 Villigen, Switzerland \\ ${ }^{c}$ Mass Spectrometry in Reactive Flows - Thermodynamics (IVG), University of Duisburg-Essen, \\ Duisburg, Germany
}

\section{Keywords}

Laminar flame; PEPICO; Mass spectrometry; H-abstraction; branching ratios; radicals

\begin{abstract}
The radicals produced by hydrogen abstraction in the initial fuel decomposition step are essential in combustion kinetics, but their experimental detection is very challenging. Imaging photoelectron photoion coincidence spectroscopy enables the detection and identification of even these isomeric radicals. Laminar low-pressure (40 mbar) hydrogen flames doped with different alkanes and alkenes are investigated systematically with the goal to identify the formation pathways and the fate of fuel radicals formed in hydrogen abstraction reactions. The abstraction reactions of primary, secondary, tertiary, and vinylic $\mathrm{H}$ atoms were never target of a systematic, direct semiquantitative investigation in a flame environment and this paper describes such a study for the first time. Performing the measurements at the vacuum ultraviolet beamline located at the Swiss Light Source enables isomer-selective detection of reactive radical species by imaging photoelectron photoion coincidence spectroscopy. For unambiguous identification of several isomeric radicals, threshold photoelectron spectra were compared with reference photoelectron spectra. $\mathrm{H}$-abstraction ratios of isomeric radicals were determined and compared to literature reaction barriers and rate coefficients. In addition to the quantitative information, the peak positions of the profiles of radicals formed by hydrogen abstraction or addition to the fuel molecules as function of distance from the burner show faster $\mathrm{H}$-abstraction for unbranched alkanes and alkenes than for branched fuels and faster $\mathrm{H}$-addition than $\mathrm{H}$-abstraction, respectively.
\end{abstract}

\footnotetext{
* Corresponding author.

Email address: Dominik.Krueger@dlr.de
} 


\section{Introduction}

A key reaction most decomposition processes in pyrolysis as well as in combustion of hydrocarbons is the abstraction of a $\mathrm{H}$ atom (referred to as $\mathrm{H}$-abstraction) by small radicals like $\mathrm{O}, \mathrm{OH}$, and $\mathrm{H}$ forming a radical (i.e., fuel radicals in the following). In particular, the initial fuel destruction steps in laminar low-pressure flames are dominated by these $\mathrm{H}$-abstraction reactions [1] and are important for ignition processes [2-4]. Because the following reaction steps are highly dependent on the type of the formed radicals, the knowledge on H-abstraction pathways is essential for understanding and predicting combustion properties. The following reaction steps are dominated by oxygen addition, to form oxygenated species like alcohols, aldehydes, ethers etc., and further decomposition steps like abstraction of $\mathrm{H}$ atoms or hydrocarbons.

$\mathrm{H}-\mathrm{abstraction}$ reactions of different hydrocarbons were the focus of several theoretical [5-10] and experimental studies [11-18]. Khaled et al. have investigated the reactions of linear alkenes [11] and $i$-butene [12] with $\mathrm{OH}$ radicals in shock tubes and showed that the reaction rate coefficients are dependent on the chain length and the position of the double bond, that is, the constitutional isomer. For example, the formation of the 2-methylallyl radical from $i$-butene is the dominating reaction channel. Zhou et al. presented in their study on $i$-butene [13] that the reactivity of the different abstraction reactants, such as $\mathrm{H}, \mathrm{O}, \mathrm{OH}$, and $\mathrm{CH}_{3}$ radicals, is mainly governed by the temperature. On the other hand, $\mathrm{Li}$ et al. investigated the oxidation process of 1-butene [14] by measuring ignition delay times and developed a chemical kinetic mechanism based on previous 2-butene [19] and $i$-butene [13] models. Zhang et al. used mass spectrometry [15] to investigate the pyrolysis of the butene isomers and found by reaction flux analysis that the decomposition of $i$-butene mainly proceeds through the 2-methylallyl radical via $\mathrm{H}$-abstraction by small radicals. For the decomposition of 1-butene, fuel radicals formed by $\mathrm{H}$-abstraction are not as relevant as the direct unimolecular scission of a $\mathrm{CH}_{3}$ group in high-temperature environments [15]. Manion et al. [16] investigated $\mathrm{H}$-abstraction reactions of $n$-alkanes by $\mathrm{H}$ and $\mathrm{CH}_{3}$ radicals and showed a strong temperature dependence of the ratio between primary and secondary H-abstractions. The Habstraction by $\mathrm{CH}_{3}$ radicals from ethane was the target of the investigations by Möller et al. [17], while the decomposition of butane isomers by $\mathrm{H}$ radicals was investigated by Peukert et al. [18] in a shock tube study.

Complementary to the experimental studies, some theoretical investigations on H-abstractions are available. Extensive studies of these reactions at different alkane $\mathrm{H}$ sites were performed by 
Carstensen et al. [7] and Badra et al. [8]. A purely theoretical investigation on H-abstraction barriers of different alkanes by $\mathrm{O}\left({ }^{3} \mathrm{P}\right)$ was published by Troya who came to the conclusion that the $\mathrm{H}$-abstraction barrier in $(\mathrm{O}+$ acyclic alkanes $)$ reactions decreases in the following order: primary $>$ secondary $>$ tertiary, without being affected by the chain length [6]. Siddique et al. recently presented a theoretical study on the $\mathrm{H}$-abstraction by amine radicals $\left(\mathrm{NH}_{2}\right)$ for a broad range of different hydrocarbons and obtained rate constants and standard enthalpies of activation [5].

While most of the experimental investigations on $\mathrm{H}$-abstraction reactions in butanes and butenes were carried out using shock tubes [11-14, 16-18, 20-25], direct measurements of radical species in flame environments are still a challenging task. Schenk et al. [26], Dias et al. [27], and Oßwald et al. [28] reported molecular-beam mass spectrometric work on low-pressure, premixed, flat flames of the different butene and butane isomers. In situ flame-sampling mass spectrometric studies are one method of recording mole fraction profiles of several species in a flame environment, but the previous studies did not clearly identify isomeric compounds. Here, we present a detailed experimental study of $\mathrm{H}$-abstraction reactions using the imaging photoelectron photoion coincidence spectroscopy (iPEPICO) endstation at the vacuum ultraviolet (VUV) beamline of the Swiss Light Source (SLS) located at the Paul Scherrer Institute (PSI). This analytical method is highly adequate for investigation of combustion processes in low-pressure flames [29-32]. In particular, the capability to identify reactive intermediates, such as radicals, isomer-selectively by photoion mass-selected threshold photoelectron spectra (ms-TPES) has proven to be useful when sampling from reactive environments (e.g., pyrolysis, photolysis, or catalytic reactors $[33,34]$ ), even though scanning the photon energy is time consuming and the mass resolution of the instrument is limited compared to other mass spectrometric systems [35]. In this work, the iPEPICO setup is used to investigate the abstraction of chemically different hydrogen atoms from the hydrocarbon fuels in low-pressure hydrogen flames doped with the different alkanes and alkenes. Ethane, $n$-butane and $i$-butane were specifically targeted in a systematic approach to investigate the hydrogen atom abstraction of primary, secondary, and tertiary hydrogen atoms. In addition, 1-butene, $i$-butene, and tetramethylethylene were chosen to evaluate the abstraction of allylic and vinylic hydrogen atoms. This set of fuels allows for comparison of different reaction pathways and enables a systematic experimental approach by measuring, identifying, and quantifying the fuel radicals in low-pressure flames. Hydrogen was 
chosen as base fuel to provide sufficient $\mathrm{H}$ atoms as well as $\mathrm{OH}$ radicals and to increase the role of hydrogen abstraction or addition in the fuel destruction pathways.

\section{Experimental}

Detailed information about the iPEPICO setup used in this study is available in the literature [36] and the coupling to the flame experiment has been described in [29]. In brief, a premixed McKenna-type flat-flame burner with a $6 \mathrm{~cm}$ diameter bronze matrix was installed in a lowpressure (40 mbar) flame chamber. The gas sample was withdrawn from the flame at the centerline of the burner by a quartz nozzle. The distance between burner and nozzle tip was varied with a stepper motor to record spatial species profiles.

A molecular beam is formed at the nozzle and passes through a nickel skimmer. Due to the rapid expansion in the molecular beam, reactions are quenched immediately, and the detection of reactive species is possible. A schematic of this low-pressure flame setup is shown in the supplemental material. The pressures are $10^{-4} \mathrm{mbar}$ in the first pumping stage and $10^{-6} \mathrm{mbar}$ in the ionization chamber. Ionization of the flame-sampled molecules was performed by tunable VUV synchrotron radiation in the range of $60-250 \mathrm{~nm}(5-21 \mathrm{eV})$ at a resolving power of $E / \Delta E=1500$, as provided by a 150 lines $\mathrm{mm}^{-1}$ grating. Higher harmonic radiation was absorbed by a gas filter $\left(\mathrm{Ne}\right.$ or $\mathrm{Ar} / \mathrm{Kr}$ ) or a $\mathrm{MgF}_{2}$ window depending on the actual photon energy.

Ions and electrons are detected in delayed coincidence using velocity map imaging and time-offlight mass spectrometry. A multistart-multistop [37] approach was applied to correlate electrons and ions. Species are identified at a constant burner position, while the photon energy was scanned over the ionization threshold of interest and photoelectrons and photoions are recorded in coincidence. Electrons without kinetic energy hit the center of the detector. Electrons with kinetic energies are imaged as concentric rings with increasing diameter for ionization events with increasing difference between photon energy and ionization threshold. Electrons with more than $1 \mathrm{eV}$ kinetic energy are not detectable. This causes a non-linear electron loss effect, which must be corrected or only measurements below $1 \mathrm{eV}$ above the ionization threshold can be used for quantitative evaluation based on literature ionization cross sections. Mass-selected photoionization efficiency (PIE) spectra (not shown in this work) or threshold photoelectron spectra (ms-TPES) (near zero kinetic energy; $E_{\text {kin }}>30 \mathrm{meV}$ ) with a resolution of better than $5 \mathrm{meV}$, which is superior to conventional ultraviolet photoelectron spectra (UPS), were obtained by selecting the electron signal measured in coincidence with the ions in the $m / z$ range of interest. 
The mass separation of the photoions was performed by time-of-flight (TOF) analysis with a mass resolution of $m / \Delta m=300$. Quantitative evaluation of species concentrations or mole fractions is based on the ion signal (for a specific $\mathrm{m} / \mathrm{z}$ ) recorded at specific photon energies in coincidence with all detectable electrons. Spatial species profiles are measured as a function of the distance between the sampling nozzle and the burner surface, also known as height above burner (HAB), with constant photon energy. Photon energies were chosen so that no electron losses had to be considered for the profiles shown in this work.

Hydrogen flames were doped with the respective hydrocarbon fuels and had the same stoichiometry of $\Phi=1.25$. Conditions were chosen to keep the carbon flow, the stoichiometry, and the $\mathrm{C} / \mathrm{H} / \mathrm{O}$ ratio constant. Because of the almost identical reaction enthalpy of the reactant mixture, the flame temperature is expected to be similar for all flames. Calibrated mass flow controllers metered the gas flows with an absolute uncertainty of $\pm 5 \%$. The pressure in the burner chamber was set to 40 mbar for all flames and controlled by a throttle valve with an accuracy of \pm 0.1 mbar. The investigated flame conditions are summarized in table 1 .

Table 1. Inlet conditions of the measured flames. sccm: standard cubic centimeter per minute (1013 mbar, $273 \mathrm{~K}$ )

\begin{tabular}{|l|l|l|l|l|}
\hline & $\mathrm{H}_{2}[\mathrm{sccm}]$ & $\mathrm{O}_{2}[\mathrm{sccm}]$ & $\mathrm{Ar}[\mathrm{sccm}]$ & Fuel [sccm] \\
\hline$n$-butane & 1700 & 1200 & 1000 & 100 \\
\hline$i$-butane & 1700 & 1200 & 1000 & 100 \\
\hline 1 -butene & 1800 & 1200 & 1000 & 100 \\
\hline$i$-butene & 1800 & 1200 & 1000 & 100 \\
\hline ethane & 1600 & 1200 & 1000 & 200 \\
\hline tetramethylethylene & 1800 & 1200 & 1000 & 67 \\
\hline
\end{tabular}




\section{Data analysis}

Quantitative data analysis follows previous works of Oßwald [29] and Cool [38]. Ion signals of interest are integrated over a single (nominal) $\mathrm{m} / \mathrm{z}$ ratio. For ms-TPES, the ions are restricted to coincidences with threshold electrons. Because energetic electrons are not considered in msTPES measurements, long integration times of up to 600 seconds per energy step may be necessary. For spatial profiles, the total ion signal of the respective mass is used. Depending on photon energy, integration times for these so-called burner scans vary between $30 \mathrm{~s}$ and $300 \mathrm{~s}$ for scans at $16 \mathrm{eV}$ and $9 \mathrm{eV}$, respectively. Major species are calculated by internal calibration [29]. The exhaust gas composition is calculated based on the $\mathrm{C}, \mathrm{H}$, and $\mathrm{O}$ balance and the photoionization cross sections of $\mathrm{CO}$ and $\mathrm{CO}_{2}$. This exhaust gas composition can be used with the measured ion signal profiles to determine mole fraction profiles. Note that the element balance is generated including Ar, all reactants, major products, and the radicals $\mathrm{O}, \mathrm{H}$, and $\mathrm{OH}$ obtained by partial thermodynamic equilibria. All other mole fractions $\left(x_{\mathrm{i}}\right)$ are evaluated from the ion signal $\left(S_{\mathrm{i}}\right)$. Specific scan factors $c(\mathrm{E})$ are used to account for systematic changes of the systems response at the given energy and to link the measured signal to argon as reference species $\left(x_{A r}, S_{A r}\right)$ originating from a $16 \mathrm{eV}$ burner scan.

$$
\begin{gathered}
\text { (1) } \frac{\mathrm{x}_{\mathrm{i}}}{\mathrm{x}_{\mathrm{Ar}}}=\frac{\mathrm{S}_{\mathrm{i}}(\mathrm{E})}{\mathrm{s}_{\mathrm{Ar}}(16 \mathrm{eV})} \cdot \frac{\sigma_{\mathrm{Ar}}(16 \mathrm{eV})}{\sigma_{\mathrm{i}}(\mathrm{E})} \cdot \frac{1}{\mathrm{c}\left(\mathrm{E}_{\mathrm{fuel}}\right)} \cdot \frac{1}{\mathrm{c}(\mathrm{E})} \\
\text { with } \\
\text { (2) } c(E)=\frac{S_{j}(E) \cdot \sigma_{j}\left(E_{R}\right)}{S_{j}\left(E_{R}\right) \cdot \sigma_{j}(E)} \cdot c\left(E_{R}\right)
\end{gathered}
$$

Here, $\sigma_{\mathrm{i}}(\mathrm{E})$ is the ionization cross section for the species $\mathrm{i}$ and the photon energy $\mathrm{E}$ and $\mathrm{j}$ is a calibration species that has no signal loss due to the electron detector energy limit in the photon energy range between $E$ and $E_{\mathrm{R}}$. A list of photon energies, for which spatial profiles were recorded, and the species used for determination of the scan factors are given in the supplemental material. Several experimental parameters are combined to the scan factor $c(E)$ (VUV-beam intensity, detection efficiencies, integration time etc.), which has to be derived step by step for all measured energies using equation (2). $E_{R}$ is the photon energy of the $c(E)$ derived before. The initial scan factor $c\left(E_{\text {fuel }}\right)$, used for the quantification of the fuel (e.g. $12.3 \mathrm{eV}$ for ethane) and consequently the first value for $c\left(E_{\mathrm{R}}\right)$, was determined using the known mole fractions for the fuel and Ar from the major species quantification and Eq. 1 with $E=E_{\text {fuel }}$ and $c(E)=1$. For the butenes, ethane, and tetramethylethylene, measurements of a known mixture of calibration species were performed for a broad range of energies and the signal ratios between two energies 
were used instead of the literature ionization cross sections for the determination of the scan factors to reduce the uncertainties of the use of literature ionization cross sections for these species. These calibration measurements reduce the impact of device-specific features like the electron loss effect.

The resulting uncertainties in the mole fractions are primarily caused by the photoionization cross sections and are dependent on the number of scan factors used in the calculation. The uncertainty in cross sections reported in the literature is usually below $30 \%$. We estimate that our calibration measurements have similar uncertainty, which leads to approximately $30 \%$ uncertainty of directly calibrated mole fractions. In general, we estimate the uncertainties of the major species to about $10 \%$ and of the intermediates with known ionization cross section to about $30-60 \%$. Other sources of uncertainty like false coincidences and uncertainties in the gas flows can be neglected. Since no photoionization cross sections are known for the fuel radicals discussed below, the absolute mole fractions are associated with enhanced uncertainties (up to a factor of 10). For the branching ratios, we assume significantly smaller uncertainties. The reason is the assumption and use of equal ionization cross sections for the radicals and relative errors between the radicals can be expected to be small enough for the present analysis. Based on the observations of Koizumi it is very likely that the ionization cross sections of two radicals will have the same magnitude. Independent of the absolute values of the ionization cross sections (here assumed to be $10 \mathrm{Mb}$ ) the ratios will have a higher confidence. A relative comparison of the profile shapes is still instructive as shown below and the order of magnitude of the mole fractions will be correct. In general, for species with unknown ionization cross sections, a value of $10 \mathrm{Mb}$ was estimated. Koizumi has estimated equal ionization cross sections of $10 \mathrm{Mb}$ as a typical photoionization cross section value for organic compounds at photon energies of $0.5 \mathrm{eV}$ to $1 \mathrm{eV}$ above the adiabatic ionization threshold [39]. The fuel radical mole fraction profiles reported here were measured at photon energies of $0.5 \mathrm{eV}$ to $0.7 \mathrm{eV}$ above the adiabatic ionization threshold close to the first vertical ionization threshold. Using the first vertical ionization threshold enables a better separation of isomers with adiabatic ionization threshold differences below $1 \mathrm{eV}$, than a fix value above the adiabatic threshold.

Kinetic modeling, when used for interpretation for the experimental data, was performed ö [40] with the kinetic mechanism AramcoMech 2.0 for combustion of $\mathrm{H}_{2} / \mathrm{CO} / \mathrm{C}_{1}-\mathrm{C}_{4}$ compounds from the Combustion Chemistry Centre in NUI Galway [19]. This combustion mechanism is well- 
validated and can predict the decomposition and destruction pathways of branched and unbranched $\mathrm{C} 1-\mathrm{C} 4$ fuels in flames. Introduction of the sampling nozzle disturbs the flame, for example, by lowering the temperature [41], by sucking gases from different positions in the flame [42], and by blocking diffusion pathways. The effect on the temperature change on the signal strength can be obtained from the pressure gradient in the ionization chamber $\left(\mathrm{p}_{\text {ion }}\right)$ during a burner scan, which reflects the sampling rate and consequently the temperature in the flame in the presence of the nozzle. The relation between the pressure and the temperature is given by [43]:

$$
p_{\text {ion }} \approx C \cdot \sqrt{\frac{\gamma}{\bar{M} \cdot T}} \cdot\left(\frac{2}{\gamma+1}\right)^{Z} \text { with } Z=\frac{(\gamma+1)}{2 \cdot(\gamma-1)}
$$

where $\gamma$ is the adiabatic index $\left(C_{\mathrm{p}} / C_{\mathrm{v}}\right), \bar{M}$ the mean molecular weight, and $\mathrm{C}$ an apparatus constant, which is determined by thermocouple exhaust gas temperature measurements. The exhaust gas temperature was $1600 \mathrm{~K}$ in the $n$-butane-doped flame. The resulting perturbed temperature profile is given in the supplemental material. The temperature profile/exhaust gas temperature is identical for all flames and we used this temperature profile in all simulations.

\section{Results and discussion}

The following section has three parts: First, it is confirmed that the main species of flames with different dopants are identical and that they can be reproduced by simulations. Second, the different fuel radicals are identified and quantified. Finally, the fuel radical formation is discussed and compared to reaction barriers and reaction rate coefficients.

\subsection{Major species and flame validation}

Six low-pressure hydrogen flames doped with several hydrocarbons have been investigated using the iPEPICO flame setup. Figure 1 shows the major species profiles of the $i$-butene- (left) and $n$-butane-doped $\mathrm{H}_{2}$ flames (right) as examples to demonstrate the quality of the measured data by comparison with initial model predictions. The major species profiles are almost identical for all flames as shown in Fig. 1 for $i$-butene and $n$-butane as examples for two of the investigated substance classes. These similarities prove the concept of getting comparable flame conditions by using equivalent element composition. The observation is consistent with temperature measurements that yield almost identical exhaust gas temperatures for the ethylene and the $n$-butane-doped flames. The major species profiles are in reasonable to good agreement with the initial predictions of the AramcoMech 2.0 kinetic model [19]. There are some discrepancies very 
close to the burner surface, which can be caused by nozzle perturbation. In the simulation, the peak position is predicted at smaller distances, which may be a temperature effect. In addition, the distortion of the flame by the sampling probe is particularly high for small burner-probe distances. The largest deviations are seen in all investigated flames between the hydrogen signal and the corresponding model predictions in the region near the burner. These discrepancies might also be related to the high diffusion rate of hydrogen.

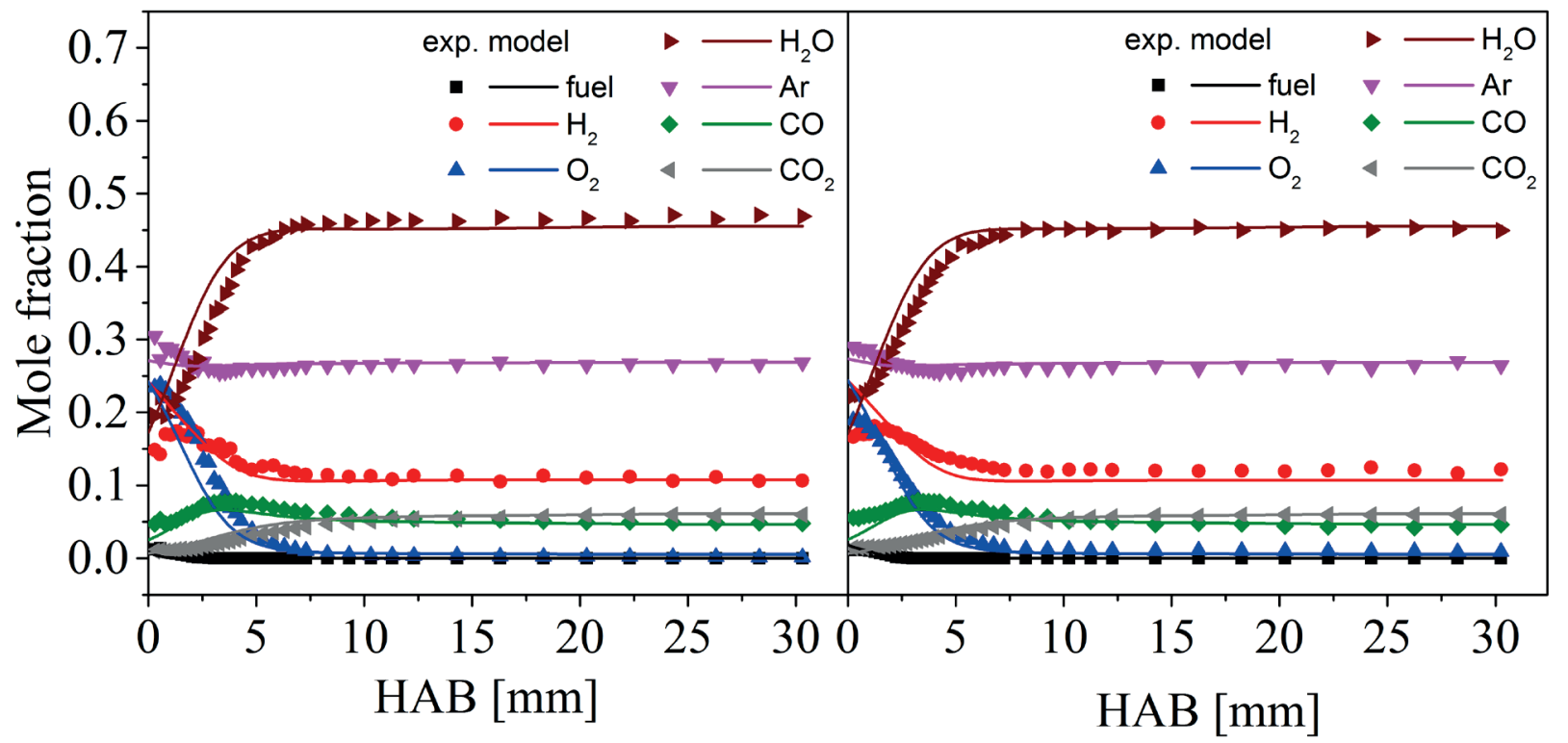

Fig. 1. Major species profiles in the $i$-butene- (left) and $n$-butane-doped (right) $\mathrm{H}_{2}$ flames versus the height above the burner (HAB) in comparison with the model predictions of the AramcoMech 2.0 mechanism [19].

Because these data demonstrate that the characteristics of the flame system are in agreement with the tested mechanism, the experimental setup and conditions are regarded as suitable for the investigation on fuel radicals.

\subsection{Fuel radical identification}

The initial H-abstraction reaction and the formation of the respective radical species is the focus of this study. While ethane and tetramethylethylene can just form one radical isomer by the abstraction of a primary or allylic hydrogen atom, the hydrogens in both butanes and butenes are not equivalent and can yield at least two different isomeric fuel radicals each. All fuel radicals of the butanes and butenes are also subject to intramolecular transfer of a methyl group, which was 
suggested by different researchers $[15,20,26]$. Figure 2 shows the H-abstraction pathways and the possible resonance structures as well as the rearrangement reactions for all investigated hydrocarbons. The resulting radical species $\left(\mathrm{C}_{4} \mathrm{H}_{9} \mathrm{~m} / z=57\right.$ and $\mathrm{C}_{4} \mathrm{H}_{7} \mathrm{~m} / z=55$, respectively) are confirmed by the ms-TPE spectra in Fig. 3 , taken in hydrogen flames doped with $n$-butane, $i$ butane, $i$-butene, and 1-butene.

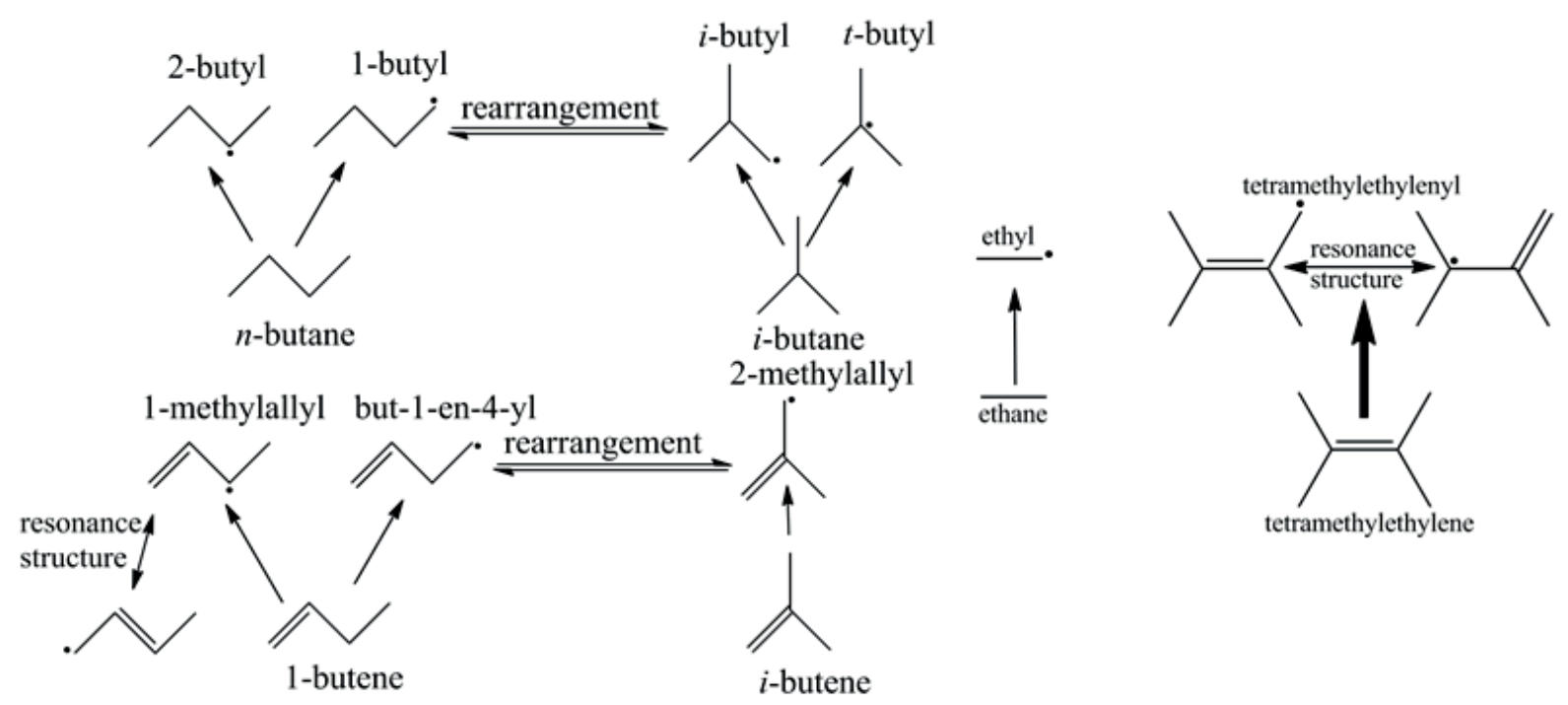

Fig. 2. Observed reaction pathways of different $\mathrm{H}$-abstraction pathways for the investigated butane and butene isomers as well as possible rearrangement reactions.

TPES measured in the flames are compared to reference photoelectron spectra of the expected radical species [44-46] for assignment of the individual isomers. The ms-TPES measured in the $n$-butane flame has an intense peak near $7.5 \mathrm{eV}$, which can be assigned to the 2-butyl radical, while the $t$-butyl radical cannot be observed. Due to the similarity between the PE spectra of $i$-butyl and the 1-butyl, the explicit identification of these two radicals is not straightforward. Although the PES of 1-butyl is in a better agreement with the recorded spectrum, the presence of the $i$-butyl radical cannot be excluded but its formation is less likely because it cannot be formed directly by hydrogen abstraction. 


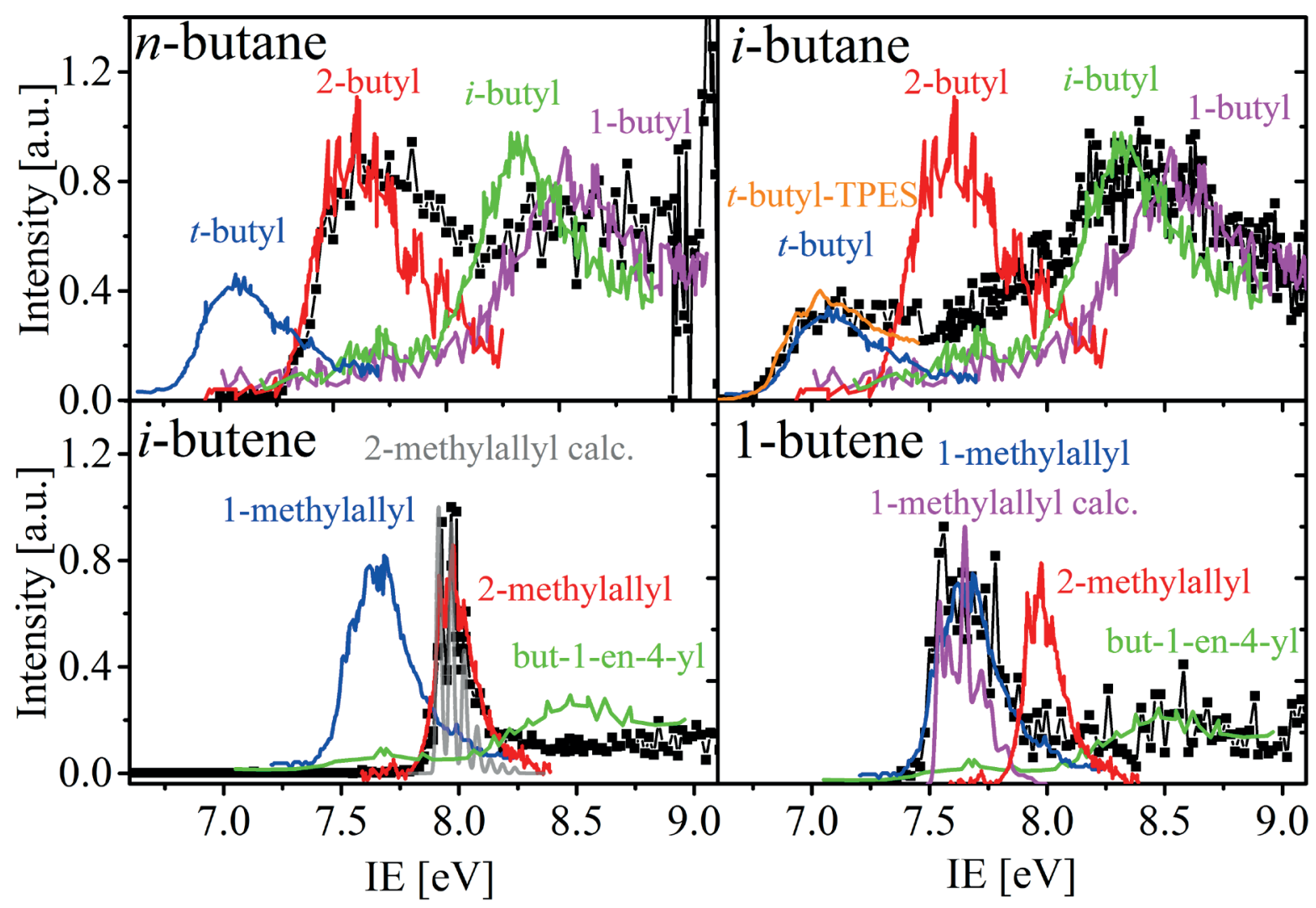

Fig. 3. Top: TPE spectra of $m / z=57\left(\mathrm{C}_{4} \mathrm{H}_{9}\right)$ from the $n$-butane- (left, HAB $\left.=0.5 \mathrm{~mm}\right)$ and $i$ butane-doped (right, HAB $=0.75 \mathrm{~mm}$ ) flames together with reference PE spectra of 1-butyl [44], 2-butyl [44], $i$-butyl [44], and $t$-butyl [45] as well as a measured TPE spectra of $t$-butyl [33]. Bottom: TPE spectra of $\mathrm{m} / z=55\left(\mathrm{C}_{4} \mathrm{H}_{7}\right)$ from the $i$-butene- (left, $\left.\mathrm{HAB}=0.75 \mathrm{~mm}\right)$ and 1-butenedoped (right, $\mathrm{HAB}=0.5 \mathrm{~mm}$ ) flames with reference spectra of 2-methylallyl [46], but-1-en-4-yl [46], and 1-methyllallyl [46] and calculated TPE spectra of 1-methylallyl [47] and 2-methylallyl [47].

In contrast to the $n$-butane-doped flame, the $i$-butane (top right panel) flame spectrum proves the presence of $t$-butyl radicals at $7.0 \mathrm{eV}$ clearly. No features corresponding to 2-butyl were observed near $7.5 \mathrm{eV}$, clearly indicating lower concentrations of 2-butyl than $t$-butyl in this flame. The broad signal peaking at $8.4 \mathrm{eV}$ is in good agreement with the PES of the $i$-butyl radical. Spectral features of the linear $\mathrm{C}_{4} \mathrm{H}_{9}$ radicals are not present in the spectrum. However, the formation of 2-butyl and 1-butyl radicals via rearrangement cannot be completely excluded in the $i$-butane flame due to the poor signal-to-noise ratio of the data.

The TPE spectrum of the $i$-butene (bottom right panel) flame shows an intense peak at $8.0 \mathrm{eV}$, supporting the idea that 2-methylallyl is the dominating $\mathrm{C}_{4} \mathrm{H}_{7}$ isomer in this flame. In addition, the observed vibrational structure of the measured TPE spectrum is in good agreement with the 
calculated 2-methylallyl TPE spectrum [47]. 1-Methylallyl (E- and Z-isomers) and but-1-en-4-yl radicals are absent in the $i$-butene flame. The TPE spectrum of the 1-butene-doped flame (bottom left panel), on the other hand, shows a large abundance of 1-methylallyl radicals. Note that the vibrational structure of the TPE spectra does not match well with the calculated reference spectrum [47], which may indicate different concentrations of the E- and the Z-isomers and a different temperature of the gas sample. The measured data imply a higher amount of the Eisomer than in the pyrolysis experiment of Lang et al. [47]. The features near $8.5 \mathrm{eV}$ can identify a small amount of the but-1-en-4-yl radical, while the 2-methylallyl is not formed from 1-butene in significant amounts. The TPE spectra of $m / z=55$ obtained from the butene flames indicate, like the butane flames TPE spectra, that the direct H-abstraction pathways without rearrangement reactions are the dominant initial fuel radical formation pathways. In summary, the expected radicals formed by $\mathrm{H}$-abstraction were identified by TPE spectra but there are no signs for the vinylic species. The TPE data indicate that rearrangement reactions do not change the overall radical formation processes significantly. Regarding the signal-to-noise ratios, it has to be emphasized that the spectra were obtained for radical species with expected mole fractions below $10^{-5}$. Time constraints caused by the availability of beam time and the time the flame experiment can be run in a stable mode (e.g., before gas cylinders need to be replaced) prohibit more averaging. It should be noted that the flame-sampled species are cooled only to approximately room temperature [48] due to the poorly developed molecular beam so that deviations of the peak intensities compared to literature spectra are to be expected.

\subsection{H-abstraction pathways}

Following the identification of the fuel radicals, mole fraction profiles and the respective decomposition products of the fuel radicals are measured for the butane, the butene, and the ethane-doped hydrogen flames. Due to the lack of available literature photoionization cross sections, the presented mole fractions of the radical species are estimated to be $10 \mathrm{MB}$ at the vertical ionization threshold. Using this value, the order of magnitude of each profile is expected to be captured correctly. The relative profile shapes do not depend on cross section and are particularly valuable for validating the kinetic models. With the assumption of equal photoionization cross sections at the vertical ionization threshold [39] a ratio between different fuel radicals in the same flame can be estimated from the peak height of the vertical transition in the TPE spectra. In the $n$-butane flame, 1-butyl and 2-butyl radicals are formed in equal amounts, 
while the mole fraction of the $i$-butyl radical is a factor of 2.5 larger than the mole fraction of the $t$-butyl radical in the $i$-butane flame. The ratio between 1-methylallyl and but-1-en-4-yl was determined to be $4: 1$ in the 1-butene flame and $i$-butene yields only the 2-methylally radical. The absolute mole fractions of the radicals with the lower ionization thresholds were calculated in the conventional way described in section 3 using the total ion signal of the respective mass. Combined with the mole fraction ratios between different radicals for the position of the energy scan presented in Fig. 3, the absolute mole fractions of the radicals with the higher ionization thresholds are accessible.

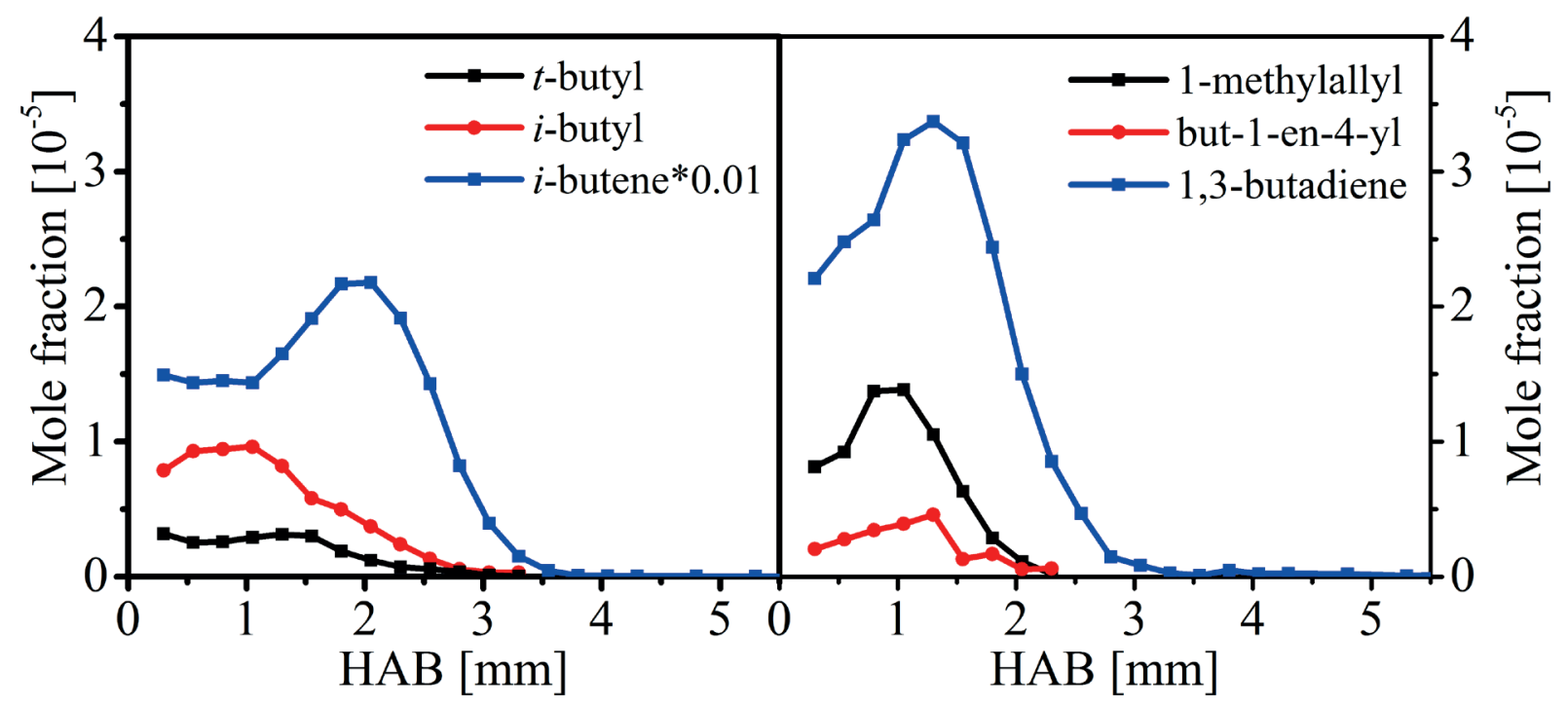

Fig. 4. Estimated mole fraction profiles of $t$-butyl (measured at $6.95 \mathrm{eV}), i$-butyl $(8.29 \mathrm{eV})$, and $i$ butene $(9.15 \mathrm{eV})$ recorded in the $i$-butane-doped flame (left side) and mole fraction profiles of the 1-methylallyl $(7.59 \mathrm{eV})$, the but-1-en-4-yl $(8.47 \mathrm{eV})$, and the 1,3-butadiene $(9.7 \mathrm{eV})$ recorded in the 1-butene-doped flame (right side) using the assumption of an equal ionization cross section $(10 \mathrm{Mb})$ for the radicals.

Figure 4 shows the species profiles of the $t$-butyl and $i$-butyl radicals as well as the decomposition product of both isomers ( $i$-butene) in the $i$-butane-doped flame (left side) and the 1-methylallyl and but-1-en-4-yl radical as well as one of their decomposition products, 1,3-butadiene, in the 1-butene-doped flame (right side). Keep in mind that the ionization cross sections for the radicals are estimated and the absolute mole fractions of the radicals are affected by huge errors (up to a factor of 10). The comparison of isomeric radicals from the same flame to gather branching ratios is a viable approach nonetheless. For both fuels, the decomposition products peak later than the related fuel radicals and the curve shapes comply with typical intermediate profile shapes. The quantification implies that the mole fractions of the stable 
decomposition products are, in comparison to the corresponding fuel radicals, larger by a factor 3 to 5 for the 1-butene and a factor 100 for the $i$-butane flame, respectively. On the other hand, there is a factor of 3 between the mole fractions of $i$-butyl and $t$-butyl and a factor of 3 between the 1-methylallyl and the but-1-en-4-yl radical. The fuel radical mole fraction profiles of the other flames are not explicitly shown here but in the supplemental material. To compare the various fuel radicals from different fuels, the type of abstracted $\mathrm{H}$ atoms, the resulting radicals, the doped fuel, the number of removable $\mathrm{H}$ atoms, the peak mole fractions $\left(\mathrm{x}_{\max }\right)$, and the peak mole fraction per abstractable $\mathrm{H}$ atom are summarized in Tab. 2. Normalizing the peak mole fraction to the number of abstractable $\mathrm{H}$ atoms eliminates the dependence on the number of equal $\mathrm{H}$ atoms and thus enables the comparison with $\mathrm{H}$-abstraction barriers.

Table 2. List of all detected fuel radicals with type of abstracted $\mathrm{H}$ atom, the name of the radical, the doped fuel, the number of abstractable $\mathrm{H}$ atoms per $4 \mathrm{C}$ atoms of this type, the maximum mole fraction, and the maximum mole fraction per $\mathrm{H}$ atom.

\begin{tabular}{|l|l|l|l|l|l|}
\hline $\begin{array}{l}\mathrm{H} \text { atom } \\
\text { type }\end{array}$ & Radical & Doped fuel & \# $\mathrm{H}$ atoms & $\mathrm{X}_{\max }$ & $\begin{array}{l}\mathrm{x}_{\max } \quad \text { per } \\
\mathrm{H} \text { atom }\end{array}$ \\
\hline primary & ethyl & ethane & 12 & $9.0 \cdot 10^{-5}$ & $7.5 \cdot 10^{-6}$ \\
\hline primary & 1 -butyl & $n$-butane & 6 & $1.7 \cdot 10^{-5}$ & $2.8 \cdot 10^{-6}$ \\
\hline secondary & 2 -butyl & $n$-butane & 4 & $1.7 \cdot 10^{-5}$ & $4.2 \cdot 10^{-6}$ \\
\hline primary & $i$-butyl & $i$-butane & 9 & $9.6 \cdot 10^{-6}$ & $1.1 \cdot 10^{-6}$ \\
\hline tertiary & $t$-butyl & $i$-butane & 1 & $3.2 \cdot 10^{-6}$ & $3.2 \cdot 10^{-6}$ \\
\hline primary & but-1-en-4-yl & 1 -butene & 3 & $4.6 \cdot 10^{-6}$ & $1.5 \cdot 10^{-6}$ \\
\hline allylic & 1 -methylallyl & 1 -butene & 2 & $1.4 \cdot 10^{-5}$ & $6.9 \cdot 10^{-6}$ \\
\hline allylic & 2-methylallyl & $i$-butene & 6 & $2.1 \cdot 10^{-5}$ & $3.5 \cdot 10^{-6}$ \\
\hline allylic & tetramethylethylenyl & tetramethylethylene & 8 & $5.8 \cdot 10^{-5}$ & $7.3 \cdot 10^{-6}$ \\
\hline
\end{tabular}

The maximum mole fractions per $\mathrm{H}$ atom for the fuel radicals of $i$-butane exhibit a ratio of $i$-butyl to $t$-butyl of 1:2.9 while for the fuel radicals of $n$-butane there is a ratio of 1-butyl to 2-butyl of 1:1.5. As expected, the $\mathrm{H}$-abstraction of primary $\mathrm{H}$ atoms is slower than of secondary and tertiary $\mathrm{H}$ atoms. Table 3 shows the $\mathrm{H}$ atom-normalized mole fraction ratios for the four butyl radicals in comparison with calculated reaction barriers for the abstraction of $\mathrm{H}$ atoms by $\mathrm{O}$ radicals provided by Troya [6] and for $\mathrm{H}$-abstraction by $\mathrm{H}$ radicals from Peukert et al [18]. For the 
reaction of $n$-butane with the $\mathrm{O}$ radicals there are no barriers available, so barriers for the formation of 1-propyl and 2-propyl by reaction of propane with $\mathrm{O}$ radicals are used to determine the ratio between primary and secondary $\mathrm{H}$-abstraction barriers. For the reaction with $\mathrm{H}$ radicals, Peukert et al. distinguished between an in-plane and out-of-plane configuration for the abstraction of the primary hydrogen atom from the fuel. Here, we only considered the in-plane configuration because the reaction barriers deviate by less than $4 \%$. The mole fraction ratios are in a qualitative agreement with the reciprocal calculated reaction barriers. In addition, the reaction barrier ratios for abstraction from the different sites of the two fuels are almost identical for the $\mathrm{O}$ and $\mathrm{H}$ atoms.

Table 3. List of literature reaction barriers from [6] and [18] compared to the maximum mole fraction ratio normalized to the number of $\mathrm{H}$ atoms.

\begin{tabular}{|l|l|l|l|l|l|}
\hline $\begin{array}{l}\text { H atom } \\
\text { type }\end{array}$ & $\begin{array}{l}\text { Meas. } \\
\text { radical }\end{array}$ & $\begin{array}{l}\text { Rel. } \\
\mathrm{x}_{\max } \text { per } \\
\mathrm{H} \text { atom }\end{array}$ & $\begin{array}{l}\text { Calc. reaction } \\
\text { barrier } \mathrm{O} \text { atom }(\mathrm{H} \\
\text { atom })[\mathrm{kcal} / \mathrm{mol}]\end{array}$ & $\begin{array}{l}\text { Relative reciprocal } \\
\text { reaction barriers } \\
\text { O atom }(\mathrm{H} \text { atom })\end{array}$ & $\begin{array}{l}\text { Calculated radical } \\
(\mathrm{O} \text { atom })\end{array}$ \\
\hline prim. & 1 -butyl & 1 & $6.93(10.07)$ & $1(1)$ & 1 -propyl (1-butyl) \\
\hline sec. & 2 -butyl & 1.52 & $4.98(7.21)$ & $1.39(1.39)$ & 2 -propyl (2-butyl) \\
\hline prim. & $i$-butyl & 1 & $6.55(10.03)$ & $1(1)$ & $t$-butyl $(i$-butyl $)$ \\
\hline tert. & $t$-butyl & 3 & $3.31(5.11)$ & $1.97(1.97)$ & $t$-butyl $(t$-butyl $)$ \\
\hline
\end{tabular}

A qualitative reciprocal correlation can be observed for the radicals formed in the 1-butene flame. The maximum mole fractions per $\mathrm{H}$ atom determined for the resonance-stabilized allylic radical 1-methylallyl is 4.6 times higher than for the primary but-1-en-4-yl radical. The reaction barrier calculated by Vasau et al. [49] for the abstraction of the allylic $\mathrm{H}$ atom from 1-butene by $\mathrm{OH}$ radicals is with $1.59 \mathrm{kcal} / \mathrm{mol} 2.4$ times smaller than for the abstraction of the primary $\mathrm{H}$ atom with $3.84 \mathrm{kcal} / \mathrm{mol}$. The experimental data confirm that inductive (primary vs. secondary vs. tertiary) and mesomeric (allylic vs. non-resonance-stabilized) effects are not diminished in systems with very high $\mathrm{H}, \mathrm{O}$, and $\mathrm{OH}$ radical concentrations. Concluding, the experimental mole fraction ratios are reflected well in a qualitative way by the reaction barriers, even though the absolute numbers differ. An explanation for these differences is, that reaction barriers of the $\mathrm{H}$ abstraction only affect the formation of the radicals but not the consumption reactions.

Since no experimental evidence for the presence of vinylic radicals was found, a comparison to the respective reaction barriers is obsolete. The respective vinylic abstraction barrier is with 
$8.02 \mathrm{kcal} / \mathrm{mol}$ (primary vinyl) and $5.70 \mathrm{kcal} / \mathrm{mol}$ (secondary vinyl) about 5 or 3.6 times higher than for the abstraction leading to the allylic radical. Based on the relationship between reaction barrier and $\mathrm{H}$-abstraction ratio from above, the absence of vinylic fuel radicals is reasonable because its mole fraction is most likely below the detection limit of the experiments performed here.

In the following, we compare the total maximum mole fractions with reaction rate coefficients from the literature. Notice that only the formation process by $\mathrm{H}$-abstraction is observed and decomposition reactions are ignored. The fuel radicals peak between $0.25-2 \mathrm{~mm}$ and in a temperature range of $700-900 \mathrm{~K}$ (see the temperature profile in the supplemental material). In this temperature range, the $\mathrm{H}$-abstraction competes with oxygen addition reactions and unimolecular scission reactions. In the present work, the aim is the abstraction of $\mathrm{H}$ atoms.

The two important $\mathrm{H}$-abstraction reactions are the reactions with $\mathrm{H}$ and $\mathrm{OH}$ radicals, because these radicals reach mole fractions of $6 \%(\mathrm{H})$ and $1 \%(\mathrm{OH})$ in the exhaust gas (see Fig. S3 in the supplemental material) and have comparatively large mole fractions in the flame front. Due to the fact that reaction rates depend on the rate constants and the concentration of the reactants, reaction rates for reactions involving both radicals will be high. In the following, the data will be used to discover and discuss reaction trends.

Figure 5 shows the Arrhenius plots of reaction rate coefficients for the reaction of $n$-butane and $i$ butane with $\mathrm{H}$ and $\mathrm{OH}$ radicals in the temperature range of 500 to $1000 \mathrm{~K}$. For the reaction of $n$ butane with these radicals, the reaction rate coefficients taken from the AramcoMech 2.0 mechanism [19] and several literature reaction rate coefficients [16, 18, 50-53] a clear preference for the formation of 2-butyl between $700-900 \mathrm{~K}$. This preference does not reflect the experimental data in this temperature range, for which a mole fraction ratio between 1-butyl and 2-butyl of 1:1 was observed in the $n$-butane flame. The experimentally observed mole fraction ratio of 3:1 between $i$-butyl and $t$-butyl radicals in the $i$-butane flame matches well to the reaction rate coefficients for the reaction of $i$-butane with $\mathrm{OH}$ radicals but not for the reaction with $\mathrm{H}$ radicals. While the reaction with $\mathrm{H}$ radicals predicts a stronger formation of $t$-butyl, the formation of $i$-butyl by $\mathrm{OH}$ radicals is predicted as a $1.9(700 \mathrm{~K})$ to $2.4(900 \mathrm{~K})$ times stronger formation pathway. This can be a first indication that the reaction with $\mathrm{OH}$ radicals has a higher impact than the reaction with $\mathrm{H}$ radicals in the present flame environment. As shown in Fig. S6 in the supplemental material, the model predictions with the AramcoMech 2.0 indicate a clear preference of 2-butyl in $n$-butane and $t$-butyl in $i$-butane. The modeling results show the same 
trends as the reaction rates of the $\mathrm{H}$-abstraction by $\mathrm{H}$ radicals very well, while the experimental data is not matched well in terms of the branching ratios.

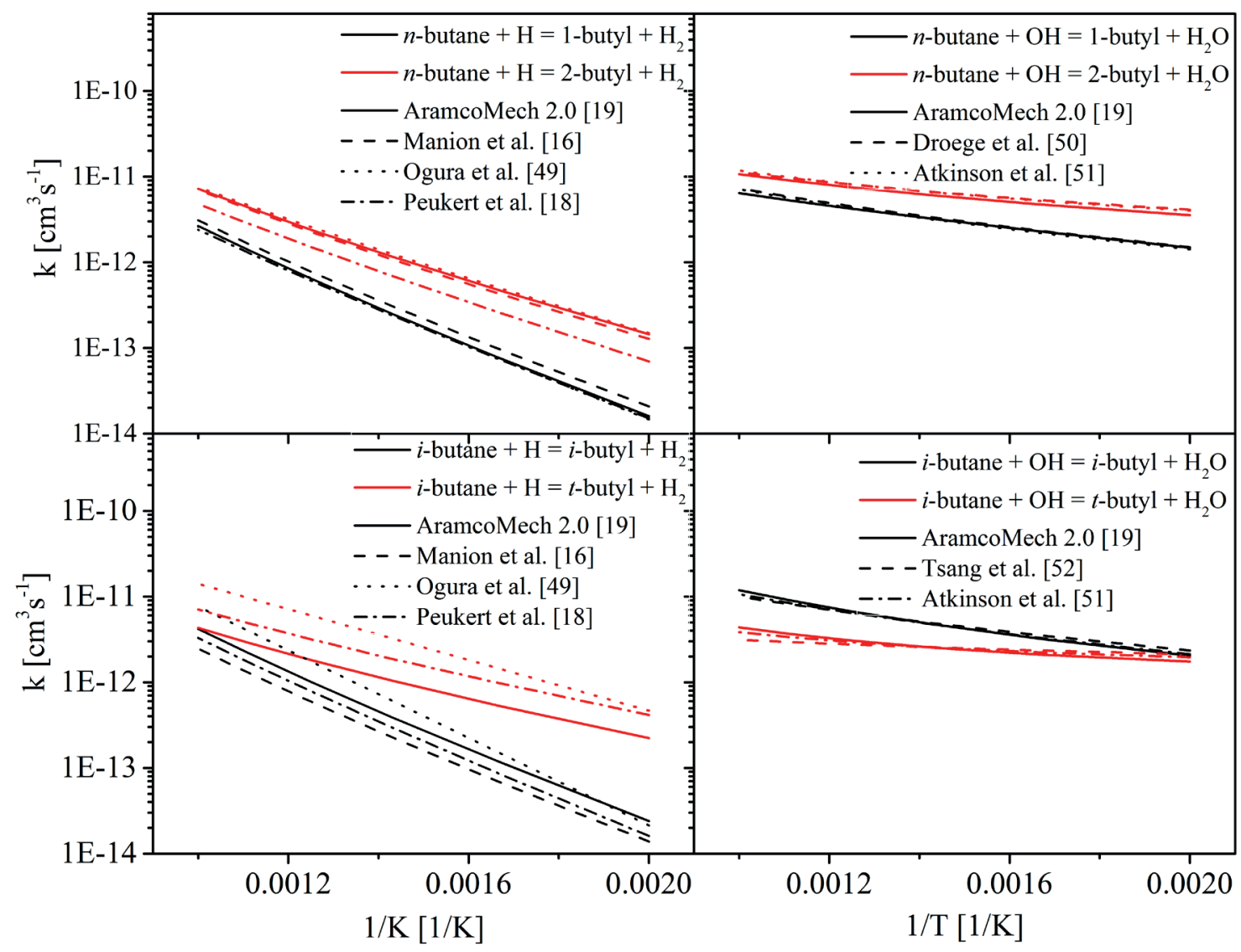

Fig. 5. Arrhenius plots of reaction rate coefficients for the reaction of $n$-butane and $i$-butane with $\mathrm{H}$ and $\mathrm{OH}$ radicals in the temperature range of 500 to $1000 \mathrm{~K}$.

For the reaction of 1-butene with the $\mathrm{H}$ and $\mathrm{OH}$ radicals, only the reaction rate coefficients taken from the Aramco mechanism are used due to the lack of other reference data. Both, the experiment (3:1) and the reaction rate coefficients (4:1 for reaction with $\mathrm{OH}$ and $2: 1$ for the reaction with the $\mathrm{H}$ radical) show a clear preference of the resonance-stabilized 1-methylallyl over the but-1-en-4-yl and are consequently in good agreement with each other. The kinetic predictions (see Fig. S6 in the supplemental material) show an even higher preference for the resonance-stabilized butenyl radical.

The reaction of $i$-butene, ethane, and tetramethylethylene will not be discussed in the same way in terms of the $\mathrm{H}$-abstraction reaction rates because these fuels can only form one radical per fuel and no radical ratios are available. In addition, no reaction rates for the H-abstraction of tetramethylethylene are available. A comparison of the reaction rates, taken from the Aramco 
mechanism for the fuels used here, shows that all reaction rates are on the same order of magnitude $\left(2.2 \cdot 10^{-13} \mathrm{~cm}^{3} \mathrm{~s}^{-1}\right.$ up to $2.4 \cdot 10^{-12} \mathrm{~cm}^{3} \mathrm{~s}^{-1}$ for reaction with $\mathrm{H}$ radicals and $2.2 \cdot 10^{-12} \mathrm{~cm}^{3} \mathrm{~s}^{-1}$ up to $7.4 \cdot 10^{-12} \mathrm{~cm}^{3} \mathrm{~s}^{-1}$ for the reaction with $\mathrm{OH}$ radicals at $800 \mathrm{~K}$ ) which is consistent with the similar mole fraction range of the experimental data.

The comparison illustrates that the rate constants in the literature deviate substantially from the data presented here. This is even true for the discussed trends. On the other hand, it is evident that the branching ratios for these reactions are reflected in the mole fraction ratios even under flame conditions. Consequently, the mole fraction ratios reported here are well suited to give some guidance on the correct trend behavior for branching ratios to be used in modeling and can be used in addition to evaluate the branching ratios between fuel destruction by hydrogen abstraction from the fuel and other fuel destruction pathways in future work. A full modeling study would allow evaluation of the rate coefficient values in the reaction network of a flame but it must be performed with care and by taking all available experimental and theoretical data on the topic of branching ratios into account. It was for this reason beyond the scope of this experimental work. A comparison of the peak positions reveals that the investigated butyl radicals are found at around $1 \mathrm{~mm}$ while their respective decomposition products systematically peak later than the fuel radicals, which is presented in Fig. 6. For the fuel radicals (Fig. 6 left side), the peak position depends mainly on the branching level of the fuels carbon backbone. While the 1-butyl and 2-butyl radicals in the $n$-butane-doped flame peak at the same distance $(0.5 \mathrm{~mm})$ both fuel radicals of the branched $i$-butane peak at higher distances ( $i$-butyl peaks at $1 \mathrm{~mm}$ and $t$-butyl peaks at $1.3 \mathrm{~mm}$ ). This shift in peak position with increasing branching level matches well with ignition delay time studies, which indicate a higher ignition delay time for $i$-butane than for $n$ butane $[24,50]$, but not with the Aramco mechanism model prediction in which all butyls peak at $1.25 \mathrm{~mm}$ and both allylic radicals peak very early at $0.25 \mathrm{~mm}$. They have no influence on the peak position. The ethyl radical formation in the ethane flame peaks at $2.3 \mathrm{~mm}$, which is at significantly higher HAB compared to the other radicals, which is in good agreement to the model predictions. A plausible explanation are lower reaction rates for the $\mathrm{H}$-abstraction from ethane $\left(5.4 \cdot 10^{-13} \mathrm{~cm}^{3} \mathrm{~s}^{-1}\right.$ for the reaction with $\mathrm{H}$ radicals for $\left.800 \mathrm{~K}\right)$ [19] than from butanes and butenes (above $1 \cdot 10^{-12} \mathrm{~cm}^{3} \mathrm{~s}^{-1}$ for the formation of all radicals except but-1-en-4-yl by reaction with $\mathrm{H}$ radicals) [19]. 


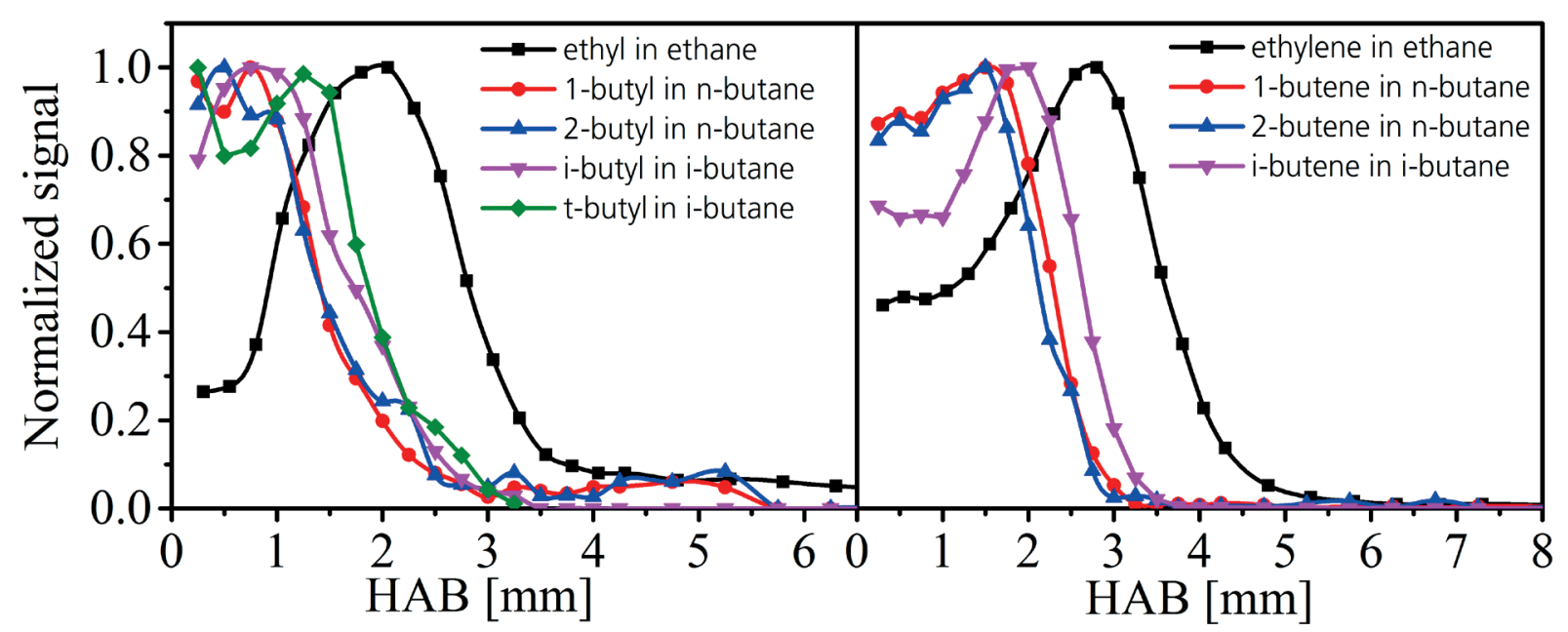

Fig. 6. Left: Normalized signal of the fuel radicals (1-butyl and 2-butyl from the $n$-butane-doped flame, $i$-butyl and $t$-butyl from the $i$-butane-doped flame, and ethyl from the ethane-doped flame). Right: Normalized signal of the further decomposition products of the fuel radicals.

This finding persists to the direct decomposition products of the respective radicals, which is presented in Fig. 6 (right): 1-butene and 2-butene are formed in the $n$-butane-doped flame and $i$ butene in the $i$-butane-doped flame. Similar to the radical species, 1-butene and 2-butene peak closer to the burner (at $1.5 \mathrm{~mm}$ ) than the decomposition product of the branched $i$-butane (at $2 \mathrm{~mm}$ ). Ethylene, as a decomposition product of the ethyl radical, peaks at $2.75 \mathrm{~mm}$. The data demonstrates that the peak order is conserved for the respective alkene decomposition products. 


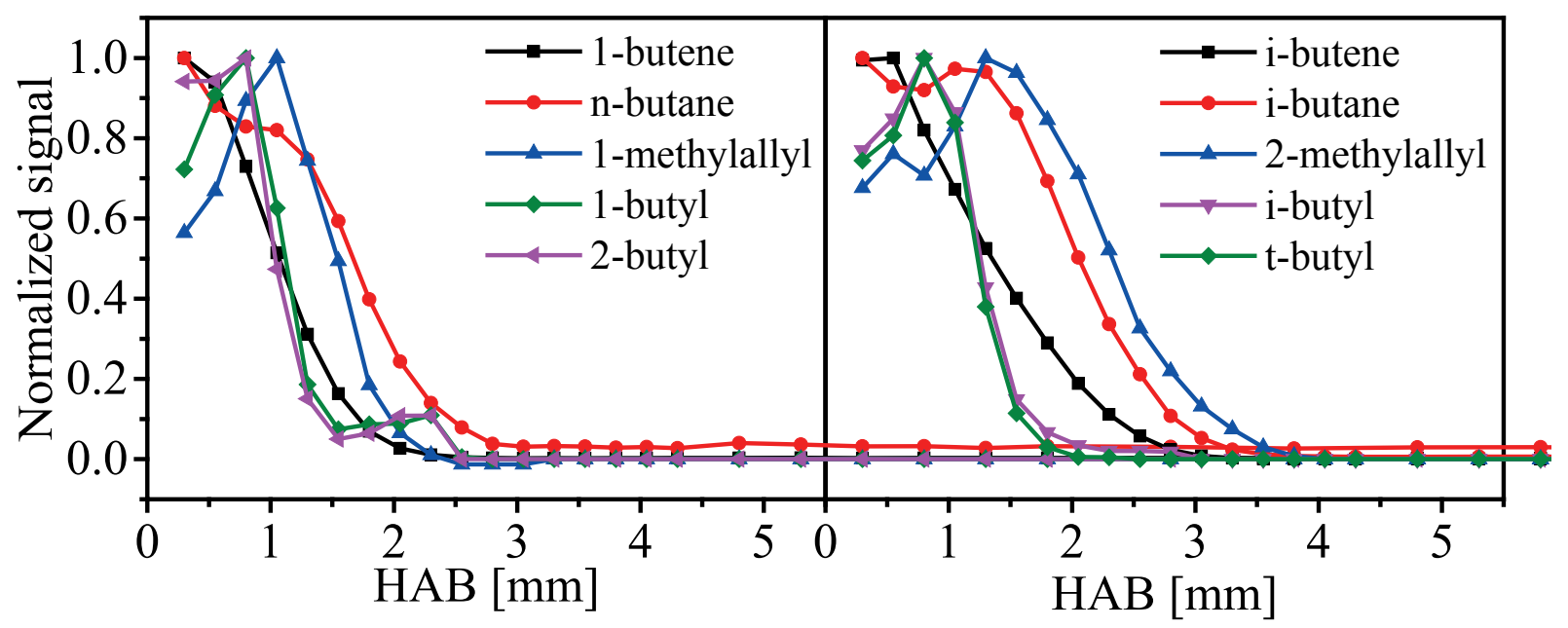

Fig. 7. Left: Normalized signal of the H-abstraction radical (1-methylallyl), the H-addition radicals (1-butyl and 2-butyl), the fuel, and the butane formed by addition of $\mathrm{H}_{2}$ in the 1-butene flame. Right: Normalized signal of the H-abstraction radical (2-methylallyl), the H-addition radicals ( $i$-butyl and $t$-butyl), the fuel, and the butane formed by addition of $\mathrm{H}_{2}$ in the $i$-butene flame.

The $\mathrm{H}$-abstraction reactions of the butenes are compared to the addition of $\mathrm{H}$ atoms to the double bond of these butenes. Figure 7 shows the normalized signals of the fuel, the H-abstraction radicals (allylic radicals), the $\mathrm{H}$-addition radicals (butyl radicals), and the butanes formed by a second $\mathrm{H}$-addition to both investigated butenes. The data demonstrate that the butyl radicals peak earlier than the allylic ones and as a result the addition of $\mathrm{H}$ atoms is significantly faster than the abstraction. Thus, the corresponding alkane is formed for both presented fuels. Figure 8 presents the reaction rate coefficients for the abstraction and the addition of $\mathrm{H}$ atoms for 1-butene. A closer look at the reaction rate coefficients indicates that the H-addition is very important in the low-temperature range below $700 \mathrm{~K}$ but decreases with increasing temperature. This finding matches with the experimental evidence of fast $\mathrm{H}$-addition at lower $\mathrm{HAB}$ and the dominating $\mathrm{H}$ abstraction at higher $\mathrm{HAB}$, and could be an explanation for the observation that the fuel radicals of the unsaturated butenes peak at larger HAB than the butyl radicals in the butane-doped flames. The simulations shown in the supplemental material indeed do not reflect this trend very well. A deeper analysis is of great interest, but far beyond the scope of this work. 


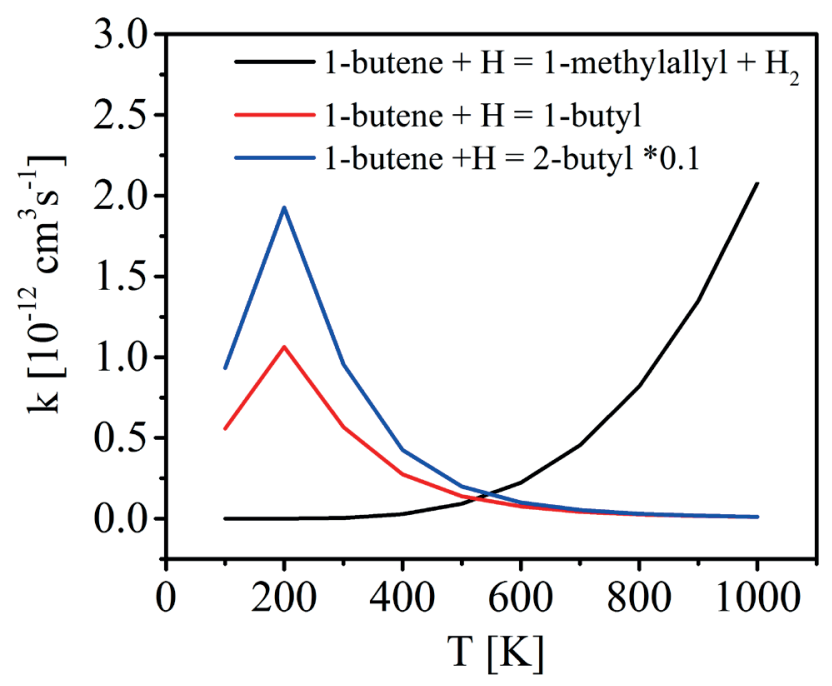

Fig. 8. Reaction rate coefficients for the $\mathrm{H}$-abstraction and the $\mathrm{H}$-addition reactions for 1-butene obtained from the AramcoMech 2.0 mechanism [19].

The H-abstraction follows clear systematics, reflected in the direct measurement of mole fraction profiles. In spite of unavailable photoionization cross sections for most of the radicals in this study, the quantification of the radical profiles via estimated similar cross sections for similar radicals was sufficient to identify the underlying trends in our experiments. Precise photoionization cross sections are needed to reduce the uncertainty in the interpretation of the branching ratios of the $\mathrm{H}$-abstraction and increase the value of presented data set for further mechanism validation.

\section{Conclusion}

Reactive radical species formed by $\mathrm{H}$-abstraction from several fuels were systematically investigated in hydrocarbon-doped low-pressure hydrogen flames by imaging photoelectron photoion coincidence spectroscopy at the Swiss Light Source in Villigen, Switzerland. Ethane, $n$-butane, $i$-butane, 1-butene, $i$-butene, and tetramethylethylene were studied to get information on hydrogen abstraction pathways. The recorded TPE spectra provide fingerprints of specific radical isomers and enable the identification of the seven dominant fuel radicals present in the flames doped with the isomeric butanes and butenes. The analysis shows that the direct $\mathrm{H}$ abstraction without rearrangement is the major reaction pathway for the formation of fuel radicals in these hydrogen-rich flames. 
Relative $\mathrm{H}$-abstraction ratios for $n$-butane, $i$-butane and 1-butene were recorded and give a clear H-abstraction order: tertiary $>$ primary; secondary $>$ primary; allylic $>$ non-resonance-stabilized form. Vinylic radicals were not observed. The comparison of the experimental data to reaction barriers from the literature shows that the mole fraction ratios of the radicals correspond to the ratio of the inverse reaction barriers. Selected literature reaction rate coefficients show a varying quality of agreement with the experimental radical mole fraction ratios. While the reaction rate coefficients for the reaction of $i$-butane with $\mathrm{OH}$ radicals are matching well with the experimental findings, the reaction rates for $n$-butane show a clear preference for the formation of 2-butyl, which is not found in the experimental data. The ratio between 1-methylallyl and but-1-en-4-yl is well reflected by the ratio of the reaction rate coefficients. In addition, the mole fraction peak positions and peak shapes were analyzed and demonstrate that unbranched hydrocarbons form the fuel radical via $\mathrm{H}$-abstraction faster and at lower temperature than branched fuels. This observation is in accordance with literature ignition delay time measurements. In comparison to the fuel radicals from the $\mathrm{C} 4$ fuels, the ethyl signal peaks significantly later in the ethane-doped flame. Furthermore, the peak mole fractions of subsequent decomposition products are shifted towards larger distances from the burner. Consequently, simulations can only reproduce the peak position of the decomposition products correctly if the model reproduces the peak position of the fuel radicals correctly. The relative mole fraction profiles can provide a very stringent test for reaction mechanisms. Finally, the addition of $\mathrm{H}$ atoms to the unsaturated fuels was investigated and the profiles reveal that the $\mathrm{H}$-addition proceeds faster than the H-abstraction.

\section{Acknowledgements}

All experiments were carried out at the VUV beamline of the Swiss Light Source of the Paul Scherrer Institute and were financially supported by the Deutsche Forschungsgesellschaft (DFG) under contract KA3871/3-1 and KO4786/2-1, the Swiss Federal Office of Energy (SFOE) under contract SI/501269-01 and has received funding from the European Community's Seventh Framework Program (FP7/2007-2013) under grant agreement n. ${ }^{\circ} 312284$ (CALIPSO)..

\section{References}

[1] J.A. Miller, M.J. Pilling, J. Troe, Unravelling combustion mechanisms through a quantitative understanding of elementary reactions, Proc. Combust. Inst. 30 (2005) 43-88.

[2] O. Welz, J. Zádor, J.D. Savee, M.Y. Ng, G. Meloni, R.X. Fernandes, L. Sheps, B.A. Simmons, T.S. Lee, D.L. Osborn, C.A. Taatjes, Low-temperature combustion chemistry of biofuels: pathways in the initial low-temperature (550 K-750 K) oxidation chemistry of isopentanol, Phys. Chem. Chem. Phys. 14 (2012) 3112-3127. 
[3] J. Zádor, C.A. Taatjes, R.X. Fernandes, Kinetics of elementary reactions in low-temperature autoignition chemistry, Prog. Energy Combust. Sci. 37 (2011) 371-421.

[4] Z. Wang, L. Zhang, K. Moshammer, D.M. Popolan-Vaida, V.S.B. Shankar, A. Lucassen, C. Hemken, C.A. Taatjes, S.R. Leone, K. Kohse-Höinghaus, N. Hansen, P. Dagaut, S.M. Sarathy, Additional chain-branching pathways in the low-temperature oxidation of branched alkanes, Combust. Flame 164 (2016) 386-396.

[5] K. Siddique, M. Altarawneh, J. Gore, P.R. Westmoreland, B.Z. Dlugogorski, Hydrogen Abstraction from Hydrocarbons by $\mathrm{NH}_{2}$, J. Phys. Chem. A 121 (2017) 2221-2231.

[6] D. Troya, Barriers of Hydrogen Abstraction from Primary, Secondary, and Tertiary Alkane Sites by O $\left({ }^{3} \mathrm{P}\right), \mathrm{J}$. Phys. Chem. A 111 (2007) 10745-10753.

[7] H.-H. Carstensen, A.M. Dean, O. Deutschmann, Rate constants for the H abstraction from alkanes (R-H) by R' $\mathrm{O}_{2}$ radicals: A systematic study on the impact of R and R', Proc. Combust. Inst. 31 (2007) 149-157.

[8] J. Badra, A. Farooq, Site-specific reaction rate constant measurements for various secondary and tertiary Habstraction by OH radicals, Combust. Flame 162 (2015) 2034-2044.

[9] R. Sumathi, H.-H. Carstensen, W.H. Green, Reaction Rate Prediction via Group Additivity Part 1: H Abstraction from Alkanes by $\mathrm{H}$ and $\mathrm{CH}_{3}$, J. Phys. Chem. A 105 (2001) 6910-6925.

[10] L.K. Huynh, S. Panasewicz, A. Ratkiewicz, T.N. Trouong, Ab Initio Study on the Kinetics of Hydrogen Abstraction for the $\mathrm{H}+$ Alkene $\mathrm{f}_{2}+$ Alkenyl Reaction Class, J. Phys. Chem. A 111 (2007) 2156-2165.

[11] F. Khaled, J. Badra, A. Farooq, A shock tube study of C4-C6 straight chain alkenes + OH reactions, Proc. Combust. Inst. 36 (2017) 289-298.

[12] F. Khaled, B.R. Giri, A. Farooq, A high-temperature shock tube kinetic study for the branching ratios of isobutene $+\mathrm{OH}$ reaction, Proc. Combust. Inst. 36 (2017) 265-272.

[13] C.-W. Zhou, Y. Li, E. O'Connor, K.P. Somers, S. Thion, C. Keesee, O. Mathieu, E.L. Petersen, T.A. DeVerter, M.A. Oehlschlaeger, G. Kukkadapu, C.-J. Sung, M. Alrefae, F. Khaled, A. Farooq, P. Dirrenberger, P.-A. Glaude, F. Battin-Leclerc, J. Santner, Y. Ju, T. Held, F.M. Haas, F.L. Dryer, H.J. Curran, A comprehensive experimental and modeling study of isobutene oxidation, Combust. Flame 167 (2016) 353-379.

[14] Y. Li, C.-W. Zhou, H.J. Curran, An extensive experimental and modeling study of 1-butene oxidation, Combust. Flame 181 (2017) 198-213.

[15] Y. Zhang, J. Cai, L. Zhao, J. Yang, H. Jin, Z. Cheng, Y. Li, L. Zhang, F. Qi, An experimental and kinetic modeling study of three butene isomers pyrolysis at low pressure, Combust. Flame 159 (2012) 905-917.

[16] J.A. Manion, D.A. Sheen, I.A. Awan, Evaluated Kinetics of the Reactions of $\mathrm{H}$ and $\mathrm{CH}_{3}$ with n-Alkanes: Experiments with $n$-Butane and a Combustion Model Reaction Network Analysis, J. Phys. Chem. A 119 (2015) 7637-7658.

[17] W. Möller, E. Mozzhukhin, H.G. Wagner, High Temperature Reactions of $\mathrm{CH}_{3} 2$ 2. H-Abstraction of alkanes, Ber. Bunsenges. Phys. Chem. 91 (1987) 660-666.

[18] S.L. Peukert, R. Sivaramakrishnan, J.V. Michael, High temperature rate constants for H/D $+n-\mathrm{C}_{4} \mathrm{H}_{10}$ and $i-$ $\mathrm{C}_{4} \mathrm{H}_{10}$, Proc. Combust. Inst. 35 (2015) 171-179.

[19] Y. Li, C.-W. Zhou, K.P. Somers, K. Zhang, H.J. Curran, The oxidation of 2-butene: A high pressure ignition delay, kinetic modeling study and reactivity comparison with isobutene and 1-butene, Proc. Combust. Inst. 36 (2017) 403-411.

[20] K. Yasunaga, Y. Kuraguchi, R. Ikeuchi, H. Masaoka, O. Takahashi, T. Koike, Y. Hidaka, Shock tube and modeling study of isobutene pyrolysis and oxidation, Proc. Combust. Inst. 32 (2009) 453-460.

[21] J. Badra, A.E. Elwardany, A. Farooq, Reaction rate constants of $\mathrm{H}$-abstraction by $\mathrm{OH}$ from large ketones: measurements and site-specific rate rules, Phys. Chem. Chem. Phys. 16 (2014) 12183-12193.

[22] L. Pan, E. Hu, J. Zhang, Z. Tian, X. Li, Z. Huang, A high pressure shock tube study of 1-butene oxidation and its comparison with n-butane and alkenes, Fuel 157 (2015) 21-27.

[23] A. Rodriguez, O. Frottier, O. Herbinet, R. Fournet, R. Bounaceur, C. Fittschen, F. Battin-Leclerc, Experimental and Modeling Investigation of the Low-Temperature Oxidation of Dimethyl Ether, J. Phys. Chem. A 119 (2015) 7905-7923.

[24] D. Healy, N.S. Donato, C.J. Aul, E.L. Petersen, C.M. Zinner, G. Bourque, H.J. Curran, Isobutane ignition delay time measurements at high pressure and detailed chemical kinetic simulations, Combust. Flame 157 (2010) 1540-

1551.

[25] D. Healy, N.S. Donato, C.J. Aul, E.L. Petersen, C.M. Zinner, G. Bourque, H.J. Curran, n-Butane: Ignition delay measurements at high pressure and detailed chemical kinetic simulations, Combust. Flame 157 (2010) 1526-1539.

[26] M. Schenk, L. Leon, K. Moshammer, P. Oßwald, T. Zeuch, L. Seidel, F. Mauss, K. Kohse-Höinghaus, Detailed mass spectrometric and modeling study of isomeric butene flames, Combust. Flame 160 (2013) 487-503.

[27] V. Dias, J. Vandooren, Experimental and modeling study of a lean premixed iso-butene/hydrogen/oxygen/argon flame, Fuel 89 (2010) 2633-2639. 
[28] P. Oßwald, K. Kohse-Höinghaus, U. Struckmeier, T. Zeuch, L. Seidel, L. Leon, F. Mauss, Combustion Chemistry of the Butane Isomers in Premixed Low-Pressure Flames, Z. Phys. Chem. 225 (2011) 1029-1054. [29] P. Oßwald, P. Hemberger, T. Bierkandt, E. Akyildiz, M. Köhler, A. Bodi, T. Gerber, T. Kasper, In situ flame chemistry tracing by imaging photoelectron photoion coincidence spectroscopy, Rev. Sci. Instrum. 85 (2014) 025101 .

[30] T. Bierkandt, P. Hemberger, P. Oßwald, M. Köhler, T. Kasper, Insights in m-xylene decomposition under fuelrich conditions by imaging photoelectron photoion coincidence spectroscopy, Proc. Combust. Inst. 36 (2017) 12231232.

[31] J. Krüger, G.A. Garcia, D. Felsmann, Kai Moshammer, A. Lackner, A. Brockhinke, L. Nahon, K. KohseHöinghaus, Photoelectron-photoion coincidence spectroscopy for multiplexed detection of intermediate species in a flame, Phys. Chem. Chem. Phys. 16 (2014) 22791-22804.

[32] J. Pieper, S. Schmitt, C. Hemken, E. Davies, J. Wullenkord, A. Brockhinke, J. Krüger, G.A. Garcia, L. Nahon, A. Lucassen, W. Eisfeld, K. Kohse-Höinghaus, Isomer Identification in Flames with Double-Imaging Photoelectron/Photoion Coincidence Spectroscopy (i ${ }^{2}$ PEPICO) using Measured and Calculated Reference Photoelectron Spectra, Z.Phys.Chem., doi:10.1515/zpch-2017-1009(2017).

[33] F. Holzmeier, M.-P. Herbert, I. Fischer, M. Steglich, A. Bodi, P. Hemberger, A photoionization study of 2propyl and t -butyl radicals, J. Anal. Appl. Pyrolysis 124 (2017) 454-460.

[34] B. Sztáray, K. Voronova, K.G. Torma, K.J. Covert, A. Bodi, P. Hemberger, T. Gerber, D.L. Osborn, CRFPEPICO: Double velocity map imaging photoelectron photoion coincidence spectroscopy for reaction kinetics studies, J. Chem. Phys. 147 (2017) 013944.

[35] N. Hansen, T.A. Cool, P.R. Westmoreland, K. Kohse-Höinghaus, Recent contributions of flame-sampling molecular-beam mass spectrometry to a fundamental understanding of combustion chemistry, Prog. Energy Combust. Sci. 35 (2009) 168-191.

[36] A. Bodi, M. Johnson, T. Gerber, Z. Gengeliczki, B. Sztáray, T. Baer, Imaging photoelectron photoion coincidence spectroscopy with velocity focusing electron optics, Rev. Sci. Instrum. 80 (2009) 034101.

[37] A. Bodi, B. Sztáray, T. Baer, M. Johnson, T. Gerber, Data acquisition schemes for continuous two-particle timeof-flight coincidence experiments, Rev. Sci. Instrum. 78 (2007) 084102.

[38] T.A. Cool, K. Nakajima, C.A. Taatjes, A. Mcllroy, P.R. Westmoreland, M.E. Law, A. Morel, Studies of a fuelrich propane flame with photoionization mass spectrometry, Proc. Combust. Inst. 30 (2005) 1681-1688.

[39] H. Koizumi, Predominant decay channel for superexcited organic molecules, J. Chem. Phys. 95 (1991) 5846-

5852.

[40] Chemical WorkBench ${ }^{\circledR} 4.0$, Kintech Laboratory, available online at

http://www.kintechlab.com/products/chemical-workbench/.

[41] A.T. Hartlieb, B. Atakan, K. Kohse-Höinghaus, Effects of a Sampling Quartz Nozzle on the Flame Structure of a Fuel-Rich Low-Pressure Propene Flame, Combust. Flame 121 (2000) 610-624.

[42] L. Deng, A. Kempf, O. Hasemann, O.P. Korobeinichev, I. Wlokas, Investigation of the sampling nozzle effect on laminar flat flames, Combust. Flame 162 (2015) 1737-1747.

[43] A. Lucassen, N. Labbe, P.R. Westmoreland, K. Kohse-Höinghaus, Combustion chemistry and fuel-nitrogen conversion in a laminar premixed flame of morpholine as a model biofuel, Combust. Flame 158 (2011) 1647-1666. [44] J.C. Schultz, F.A. Houle, J.L. Beauchamp, Photoelectron Spectroscopy of 1 -Propyl, 1 -Butyl, Isobutyl, Neopentyl, and 2-Butyl Radicals: Free Radical Precursors to High-Energy Carbonium Ion Isomers, J. Am. Chem. Soc. 106 (1984) 3917-3927.

[45] F.A. Houle, J.L.Beauchamp, Photoelectron Spectroscopy of Methyl, Ethyl, Isopropyl, and tert- Butyl Radicals. Implications for the Thermochemistry and Structures of the Radicals and Their Corresponding Carbonium Ions, J. Am. Chem. Soc. 101 (1979) 4067-4074.

[46] J.C. Schultz, F.A. Houle, J.L. Beauchamp, Photoelectron Spectroscopy of Isomeric $\mathrm{C}_{4} \mathrm{H}_{7}$ Radicals. Implications for the Thermochemistry and Structures of the Radicals and Their Corresponding Carbonium Ions, J. Am. Chem. Soc. 106 (1984) 7336-7347.

[47] M. Lang, F. Holzmeier, P. Hemberger, I. Fischer, Threshold Photoelectron Spectra of Combustion Relevant $\mathrm{C}_{4} \mathrm{H}_{5}$ and $\mathrm{C}_{4} \mathrm{H}_{7}$ Isomers, J. Phys. Chem. A 119 (2015) 3995-4000.

[48] M. Kamphus, N.-N. Liu, B. Atakan, F. Qui, A. McIlroy, REMPI Temperature Measurements in Molecular Beam Sampled Low-Pressure Flames, Proc. Combust. Inst. 29 (2002) 2627-2633.

[49] S.S. Vasu, L.K. Huynh, D.F. Davidson, R.K. Hanson, D.M. Golden, Reactions of OH with butene isomers: measurements of the overall rates and a theoretical study, J. Phys. Chem. A 115 (2011) 2549-2556.

[50] T. Ogura, Y. Nagumo, A. Miyoshi, M. Koshi, Chemical Kinetic Mechanism for High Temperature Oxidation of Butane Isomers, Energy Fuels 21 (2007) 130.-135. 
[51] A.T. Droege, F.P. Tully, Hydrogen-Atom Abstraction from Alkanes by OH. 5. n-Butane, J. Phys. Chem. 90 (1986) 5937-5941.

[52] R. Atkinson, Estimation of OH Radical Rate Constants from H-Atom Abstraction from C-H and O-H Bonds over the Temperature Range 250-1000 K, Int. J. Chem. Kin. 18 (1986) 555-568.

[53] W. Tsang, Chemical Kinetic Data Base for Combustion Chemistry Part 4. Isobutane, J. Phys. and Chem. Ref. Data 19 (1990) 1-68. 